\title{
El Derecho Político y las controversias acerca de la soberanía. Argentina, 1910- 1940
}

\section{Political Law and controversies about sovereignty. Argentina, 1910-1940}

\author{
Leandro Losada* \\ CONICET/Universidad Nacional de San Martín, Argentina \\ ORCID ID: 0000-0002-4658-0819 \\ Recibido: $\quad 11 / 05 / 2021$ \\ Aceptado: $\quad 07 / 10 / 2021$
}

DOI: https://doi.org/10.20318/cian.2021.6446

Resumen: El artículo se focaliza en las cátedras de Derecho Político, creadas en distintas universidades argentinas a partir de la década de 1910. Estas cátedras significaron una renovación en campos como la Teoría del Estado y la Historia de las Ideas Políticas. El objeto específico del trabajo son las concepciones que destacados profesores de Derecho Político desarrollaron en textos y cursos sobre la soberanía y su relación con la libertad. El artículo plantea que estas reflexiones son evidencias originales y relevantes sobre dos temas: cómo se enseñó en la universidad argentina las características y fundamentos del Estado, y qué diagnósticos se hicieron sobre los rasgos y la crisis del liberalismo en el pensamiento político argentino entre 1910 y 1940.

Palabras clave: pensamiento político; liberalismo; estado.
Abstract: The article focuses on the courses of Political Law, created in different Argentine universities from the 1910s. These courses meant a renewal in fields such as the Theory of the State and the History of Political Ideas. The specific object of the paper are the conceptions that prominent professors of Political Law developed in texts and courses on sovereignty and its relationship with freedom. The article states that these reflections are original and relevant evidence on two topics: how the characteristics and foundations of the State were taught in the Argentine university, and what diagnoses were made about the features and crisis of liberalism in Argentine political thought between 1910 and 1940. lism; state.
Keywords: political thought; libera-

\footnotetext{
*llosada@unsam.edu.ar
} 
En las primeras décadas del siglo XX, la universidad experimentó cambios importantes en la Argentina. Las transformaciones ocurrieron en diversos planos. Por un lado, surgieron nuevas casas de altos estudios, como las de La Plata (ciudad capital de la Provincia de Buenos Aires) y El Litoral, en la Provincia de Santa Fe. Por otro lado, aumentó la cantidad de estudiantes. Esto fue consecuencia del crecimiento demográfico que atravesó el país debido a una masiva inmigración ultramarina procedente, sobre todo, de Italia y de España, y, a la vez, de las expectativas de movilidad social ascendente que caracterizaron a esa sociedad inmigratoria en la que se convirtió la Argentina de inicios del siglo XX.

A su vez, hubo cambios normativos, cuyo punto culminante fue la llamada «Reforma Universitaria» de 1918. Este episodio estableció la autonomía universitaria respecto del poder político (hasta entonces, el Poder Ejecutivo Nacional intervenía en la designación de profesores), incorporó al estudiantado en los organismos de gobierno universitarios, y estableció coordenadas institucionales que favorecieron la profesionalización del campo académico ${ }^{1}$.

La ampliación y la renovación del campo universitario estuvieron acompañadas de debates y controversias acerca del perfil deseable de universidad. La contraposición entre una universidad enfocada en la formación profesional y una universidad orientada a la investigación, fue probablemente la polémica más transitada. La relación entre política y saber, y las posibilidades de una "política científica», también incidieron en las discusiones acerca del papel de la universidad, en un momento en el cual la magnitud y la velocidad de los cambios sociales (que condujeron al país a integrar el elenco de las primeras diez economías del mundo hacia 1910, o a que su población pasara de 4000000 de habitantes en 1895 a casi 8 millones en 1914), hicieron perentorio el diseño de políticas públicas que permitieran conocer e intervenir sobre un tejido social en acelerada mutación ${ }^{2}$.

Por último, la universidad argentina de inicios del siglo XX asistió a renovaciones disciplinares y epistemológicas. Una de ellas ocurrió en el campo del Derecho, y será el eje de este artículo, la aparición del Derecho Político como asignatura, e incluso como especialidad académica. Este fenómeno se relaciona con otra tendencia, la delineación de una «ciencia política», en la cual los juristas tuvieron participación destacada, y cuyo objetivo fue propo-

\footnotetext{
${ }^{1}$ Pablo Buchbinder, ¿Revolución en los claustros? La reforma universitaria de 1918 (Buenos Aires: Sudamericana, 2012); Ana Clarisa Agüero y Alejandro Eujanián, ed., Variaciones del reformismo. Tiempos y experiencias (Rosario: Universidad Nacional de Rosario, 2018).

${ }^{2}$ Eduardo Zimmermann, Los liberales reformistas. La cuestión social en la Argentina, 18901916 (Buenos Aires: Sudamericana/Universidad de San Andrés, 1995).
} 
ner un estudio de la política autónomo respecto de ciencias sociales como la sociología o la psicología, cuya visibilidad e incipiente especialización habían ganado fuerza en el cambio del siglo XIX al XX⿳3.

Las novedades en el estudio de la política, sin embargo, se entenderían parcialmente si no se las situara en un contexto más amplio que el propiamente universitario. Hubo otro tipo de incentivos para esas novedades, provenientes de las circunstancias que signaron a la vida pública. Volviendo a lo señalado en el párrafo anterior, la aparición de la «ciencia política» estuvo conectada con el debate público acerca de la reforma política y la reforma electoral desplegado en la Argentina de la década de 1910, cuyo punto culminante fue la sanción de la ley que estableció en 1912 el sufragio secreto, obligatorio y universal para la población masculina (conocida como Ley Sáenz Peña, en alusión al Presidente de la República en ese entonces) ${ }^{4}$.

En un sentido similar, la aparición del Derecho Político en sede universitaria, ocurrida a partir de los años 1920, se desplegó en un contexto político e ideológico definido por la crisis y la volatilidad. Entre 1910 y 1940, la Argentina asistió a su primera experiencia con sufragio secreto y obligatorio (como recién se indicó, se inició a causa de la reforma electoral de 1912), que coincidió con un recambio en los elencos dirigentes (el Partido Autonomista Nacional, que había controlado el poder desde 1880 fue desplazado en 1916 por la Unión Cívica Radical, el principal partido de oposición hasta entonces). Esta experiencia fue clausurada por un golpe de estado en 1930, que abrió un período caracterizado por la alternancia de proyectos autoritarios y restauraciones constitucionales fraudulentas (sobre todo, por las distorsiones acaecidas en las contiendas electorales), que a su vez se cerró en 1943 con un nuevo golpe de estado. La crisis del liberalismo y las cautelas (así como la oposición) a la democracia, fueron el marco ideológico en el que transcurrió toda esta secuencia de la vida pública argentina ${ }^{5}$.

${ }^{3}$ Jorge Myers, "La ciencia política argentina y la cuestión de los partidos políticos: discusiones en la Revista Argentina de Ciencias Políticas (1904-1916)", en Crear la democracia. La Revista Argentina de Ciencias Políticas y el debate en torno de la República Verdadera, ed. Darío Roldán (Buenos Aires: FCE, 2006); Eduardo Zimmermann, "Constitucionalismo argentino, siglos XIX y XX: poderes y derechos”, en Un siglo de constitucionalismo en América Latina (19172017), ed. Catherine Andrews (México: C.I.D.E/ Secretaría de Relaciones Exteriores/Archivo General de la Nación, 2017).

${ }^{4}$ Myers, "La ciencia política argentina". Ver también Natacha Bacolla, "A propósito de Rafael Bielsa. Semblanza para una historia de la Ciencia Política en Argentina en los inicios del siglo XX", Araucaria. Revista Iberoamericana de Filosofía, Política y Humanidades 38 (2017): 545-573.

${ }_{5}^{5}$ Tulio Halperin Donghi, Vida y muerte de la República Verdadera (Buenos Aires: Ariel, 1999); Tulio Halperin Donghi, La República Imposible (1930-1945) (Buenos Aires: Ariel, 2004); 
La crisis de la llamada "Argentina liberal", en referencia a la fractura del consenso alrededor del proyecto de Nación que había consagrado la Constitución de 1853, es, por ende, el contexto político e ideológico en el que se sitúan las intervenciones que se abordarán en las páginas que siguen. Es materia de debate historiográfico si esa ruptura debe ubicarse en el golpe de Estado de 1930, aquel que, como recién se dijo, interrumpió la primera experiencia de democracia de masas, pero, que, a la vez, no se plasmó en la instalación de un régimen antiliberal, o en el golpe de Estado de 1943, cuyo desenlace estuvo signado por la aparición del fenómeno político más importante del siglo XX argentino, el peronismo. En este artículo, la elección cronológica entre 1910 y 1940 se fundamenta en que las reflexiones acerca del liberalismo, sus rasgos doctrinarios, y su crisis, adquieren especial interés cuando se contempla en bloque el período enmarcado entre el Centenario de la Revolución de Mayo en 1910 y la década de 1940, cuando las tendencias antiliberales no sólo ganaron visibilidad ideológica sino también política ${ }^{6}$. Más allá de las opciones cronológicas, la crisis de la "Argentina liberal" es un fenómeno relevante, tanto por su conexión con la turbulenta historia política que signó al país en la segunda mitad del siglo XX, como porque el consenso acerca del liberalismo como marco ideológico y programático para la construcción de la Nación había sido tan considerable a lo largo del siglo XIX que se ha afirmado que la Argentina fue un país "nacido liberal"7.

Teniendo todo esto en consideración, este artículo aborda un objeto específico: el tratamiento que recibió la soberanía como problema político y teórico en el Derecho Político argentino de las décadas de 1910 a 1940. La elección se debe a dos razones. La primera es que la soberanía fue un tema especialmente visible en este novedoso espacio de la reflexión jurídica y política, y de la enseñanza universitaria del derecho en la Argentina. La segunda, es que las consideraciones volcadas al respecto son ilustrativas de los argumentos lanzados en defensa o en contra del liberalismo por algunos de los profesores de Derecho Político más importantes del país en el período elegido, cada uno de ellos inscripto en distintos espacios políticos y doctrinarios: Carlos Sánchez Viamonte, Faustino Legón, José Bianco y Mariano

Leandro Losada (comp.), Política y vida pública. Argentina, 1930-1943 (Buenos Aires: Imago Mundi, 2017).

${ }^{6}$ Leandro Losada, "Liberalismo y derechas en la Argentina, 1912-1943. Apuestas interpretativas, posibilidades y límites", Prismas. Revista de Historia Intelectual, 24 (2020): 219-225.

${ }^{7}$ Tulio Halperin Donghi, "Argentina: Liberalism in a Country Born Liberal", en Guiding the Invisible Hand. Economic Liberalism and the State in Latin America, eds. Joseph Love \& Nils Jacobsen (New York: Praeger, 1988), 99-117. 
de Vedia y Mitre. De esta manera, sus consideraciones ofrecen testimonios reveladores de cómo se procesó la crisis del liberalismo en el pensamiento político y en la cátedra universitaria en la Argentina.

\section{El derecho político en la Argentina y el problema de la soberanía}

La aparición del Derecho Político en la universidad argentina se dio de manera paulatina. A partir de los años 1910, empezaron a dictarse cursos en las Universidades de Buenos Aires, La Plata y Córdoba, a menudo en la modalidad de seminarios (usualmente denominados Historia de las Instituciones Representativas), para convertirse en cátedras en los años 1920 (la Facultad de Derecho de la Universidad de Buenos Aires la inauguró en 1922) ${ }^{8}$. Como afirmaba José Bianco en 1919, profesor en la Universidad de La Plata de uno de esos cursos previos a la consolidación de las cátedras: «Entre nosotros, el derecho político, confundido y entremezclado con el derecho constitucional, se ha limitado en la cátedra al examen escueto de textos nacionales y extranjeros, comparándolos entre sí con reminiscencias históricas e interpretaciones jurídicas, legislativas y administrativas» ${ }^{9}$.

El Derecho Político no fue novedad exclusiva de la universidad argentina. De hecho, puede decirse que su aparición estuvo relacionada con la afirmación del Derecho Político en otros países, y con las visitas a la Argentina de destacados profesores en la materia, como, por ejemplo, Adolfo Posada o León Duguit ${ }^{10}$. Como espacio curricular, el Derecho Político se abocó al Derecho Público y a la Teoría del Estado, pero a la vez ofreció un ámbito para

\footnotetext{
${ }^{8}$ En Córdoba, en cambio, recién se creó en 1942. Horacio Sanguinetti, "La verdad acerca de la creación del Instituto de Enseñanza Práctica", Academia. Revista sobre enseñanza del Derecho 21 (2013); Raúl Arlotti, "Las primeras lecciones de Derecho Político en la Facultad de Derecho y Ciencias Sociales de la UBA", en Nuevos Aportes a la Historia de la Facultad de Derecho de la Universidad de Buenos Aires, ed. Tulio Ortiz (Buenos Aires: Facultad de Derecho UBA, 2014); Raúl Arlotti, "Faustino J. Legón: la primera comunidad epistémica del Derecho Político en Argentina y la introducción del Derecho Político en la Universidad Nacional de La Plata", Revista Anales de la Facultad de Ciencias Jurídicas y Sociales 47 (2017); Ramón Yanzi Ferreira, "La enseñanza de Derecho Político en la Facultad de Derecho y Ciencias Sociales de la Universidad Nacional de Córdoba", Revista de la Facultad III, no. 2 (2012); Pablo Buchbinder, "De la impugnación al profesionalismo a la crítica a la Reforma: perspectivas de la Universidad", en Crear la democracia, ed. Darío Roldán.

${ }_{9}^{9}$ José Bianco, Vida de las instituciones políticas (1919) (Buenos Aires: Rosso, 1929), 36-37.

${ }^{10} \mathrm{Cfr}$. El derecho político de la Segunda República. Francisco Ayala, Eduardo L. Llorens, Nicolás Pérez Serrano. Estudio preliminar, edición y notas de Sebastián Martín (Madrid: Universidad Carlos III, 2011).
} 
que aproximaciones, perspectivas e incluso formas de conocimiento hasta entonces poco sistemáticas en la Argentina adquirieran visibilidad y espesor, como la historia de las ideas políticas. Más en general, estimuló un acercamiento filosófico, teórico e histórico al estudio del estado. Por estos motivos, la soberanía fue un tema recurrente en cursos y textos.

Ahora bien, el interés por la soberanía no se debió sólo a la aparición del Derecho Político en la universidad argentina. Fue un tema relevante en todo Occidente después de la Primera Guerra Mundial, por dos grandes motivos. Por un lado, la crisis de la democracia liberal y el surgimiento de regímenes autoritarios alentaron preguntas sobre la legitimidad y la legalidad de la decisión política, la concentración del poder, o la relación entre soberanía y libertad. La segunda razón fue la reconfiguración del estado al compás de la aparición de la sociedad de masas ${ }^{11}$. Intervenir y tratar el tema de la soberanía, por lo tanto, implicó varias operaciones en un mismo movimiento: reponer una reflexión propiamente política sobre la naturaleza y las características del estado; y pensar los desafíos y los problemas de la libertad y de la autoridad.

En este escenario, las intervenciones argentinas se sostuvieron en apropiaciones de los clásicos de la filosofía y del Derecho Político, en diagnósticos igualmente personales sobre la historia y la coyuntura local e internacional, y en matrices teóricas contemporáneas. Entre ellas sobresalen tres, que informan sobre el impacto de determinados autores y la circulación de saberes en la universidad argentina de los años 1910 a 1940: la obra de León Duguit (quien, como se indicó, dictó conferencias en Buenos Aires en 1911, de importante repercusión), que cuestionó la soberanía por su peligro para la libertad y propuso sustituirla por la noción de servicio social como clave de bóveda del despliegue de la acción estatal, redefiniendo además la noción de libertad en un sentido solidarista y concibiéndola como un deber más que como un derecho ${ }^{12}$. En segundo lugar, la teoría de la autolimitación del estado, que se apoyaba en una noción jurídica, no política, de la soberanía, y que hacía al estado (no a la nación ni a los individuos), su titular. Era una perspectiva de raíz alemana, desarrollada en la segunda mitad del siglo XIX

${ }^{11}$ Cfr. Zimmermann, "Constitucionalismo argentino".

${ }^{12}$ León Duguit, Soberanía y libertad (Madrid: Francisco Beltrán, 1924). Sobre su visita a Buenos Aires, Carlos M. Herrera, "Jean Jaures y León Duguit en Buenos Aires: el político, el científico, lo social", en Visitas culturales en la Argentina, 1898-1936, ed. Paula Bruno (Buenos Aires: Biblos, 2014). Una visión general sobre sus ideas, en Jaime Orlando Santofimio Gamboa, "León Duguit y su doctrina realista, objetiva y positiva del Derecho en las bases del concepto de servicio público", Revista digital de Derecho Administrativo 5 (2011). 
por juristas como Carl Friedrich Von Gerber, Georg Jellinek o Rudolf Von Ihering, pero también por exponentes franceses e italianos, entre ellos, Vittorio Emmanuele Orlando o Raimond Carré de Malberg. Finalmente, debe sumarse la crítica a la soberanía desplegada por el neotomismo, a partir de una recuperación del derecho natural y de la postulación de una subordinación del orden temporal a una dimensión trascendente ${ }^{13}$.

Estas perspectivas tenían, desde ya, anclajes doctrinarios y epistemológicos distintos (la teología, la reflexión jurídica, la impronta sociológica). Y contrapuntos de diferente tenor con el liberalismo. La obra de Duguit, como se dijo, tenía conexiones con el solidarismo, la variante francesa del liberalismo de orientación social y reformista, cuyas versiones se multiplicaron entre fines del siglo XIX y las décadas iniciales del siglo $\mathrm{XX}^{14}$. La teoría alemana de la autolimitación estatal, a su vez, no propuso una recusación frontal del liberalismo, sino un «estatalismo liberal» ${ }^{15}$. Asimismo, las críticas al liberalismo en el neotomismo tuvieron distinto grado y alcance ${ }^{16}$. En consecuencia, si bien en las tres perspectivas señaladas había un cuestionamiento a pilares del liberalismo clásico (por ejemplo, la noción de derechos individuales o subjetivos, o una noción garantista del estado, que contraponía soberanía a derechos), esos cuestionamientos incluyeron tanto ataques al liberalismo

${ }^{13}$ A partir de los años 30, asimismo, comenzó a advertirse en la Argentina la recepción de Carl Schmitt. La misma, sin embargo, tuvo en principio motivaciones políticas más que académicas (por ejemplo, en el nacionalismo antiliberal, espacio político-intelectual pionero en esa recepción). En segundo lugar, la recepción de Schmitt no tuvo como único ni principal móvil su estatura de teórico de la soberanía. Aunque vinculado a esta faceta, las discusiones académicas suscitadas por su obra se vincularon sobre todo con su pensamiento constitucional. En parte por ello, su impacto se acentuó en la década de 1940, ya a fines del período aquí elegido, en relación con la reforma constitucional realizada por el primer gobierno de Juan Domingo Perón en 1949. Por todas estas razones, los autores aquí estudiados, durante los años en que se concentra este trabajo, no aludieron a Schmitt, o lo hicieron sólo parcialmente. Cfr. Jorge Dotti, Carl Schmitt en Argentina (Rosario: Homo Sapiens, 2000).

${ }^{14}$ Por ejemplo, el progressivsm norteamericano, el nuevo liberalismo británico, el krausoinstitucionalismo español o las propias corrientes reformistas del liberalismo argentino de inicios del siglo XX. Cfr. Helena Rosenblat, The Lost History of Liberalism. From Ancient Rome to the Twenty-First Century (Princeton University Press, 2019): 220-244; Edmund Fawcett, Liberalism: The Life of an Idea (Princeton University Press, 2019): 147-172; Manuel Suárez Cortina (coord), Libertad, armonía y tolerancia. La cultura institucionista en España (Madrid: Tecnos, 2008); Zimmermann, Los liberales reformistas.

${ }^{15}$ Maurizio Fioravanti, Los derechos fundamentales. Apuntes de historia de las constituciones (Madrid: Trotta, 2009), 97-125.

${ }^{16}$ Olivier Compagnon, Jacques Maritain et l'Amérique du Sud. Le modèle malgré lui (Villeneuve-d'Ascq: Presses universitaires du Septentrion, 2003); José Zanca, Cristianos antifascistas: conflictos en la cultura católica argentina, 1936-1959 (Buenos Aires: Siglo XXI, 2013). 
como insatisfacciones que, antes que declarar su carácter vetusto o pernicioso, pretendieron adaptarlo a lo que se juzgaba como las circunstancias históricas y políticas imperantes.

\section{La soberanía según Carlos Sánchez Viamonte}

Carlos Sánchez Viamonte (1892-1972) fue profesor de Derecho Político en la Universidad Nacional de La Plata. Estuvo entre los fundadores de la revista Sagitario, vinculada al movimiento reformista de 1918, y fue una figura destacada del socialismo argentino. En un conjunto de artículos publicado bajo el título Derecho político (ensayos), en 1925, realizó una crítica a la soberanía, especialmente a la soberanía del pueblo ${ }^{17}$.

Sánchez Viamonte entendió que la «acepción originaria y fundamental» de la soberanía era «el poder de la voluntad general, que se manifiesta concretamente a través de un órgano propio: el Estado». Y consideró que para que ese concepto pudiera ser admisible era «indispensable aceptar la doctrina del pacto social» ${ }^{18}$. Desde este punto de vista, definió a Jean Jacques Rousseau como el «más completo y enérgico campeón» del «dogma de la soberanía», pues con él «ya no [está] limitada por sus fines, como en Tomás de Aquino, [Francisco] Suárez o [Jean] Bodin, sino ilimitada e indivisible» ${ }^{19}$.

A partir de estas premisas, su crítica a la soberanía tenía un primer eslabón en la consideración de que el contrato social y la soberanía constituían una explicación históricamente insostenible del surgimiento del poder en la sociedad. Podía reconocerse que ambas nociones habían cumplido un rol importante, pues frente al absolutismo monárquico habían devuelto «a la sociedad el dominio de sí misma». Pero, «al procurar la demostración triunfante de que los hombres nacen libres y libremente crearon su gobierno propio, [se] desnaturalizó la realidad histórica». Pues el «gobierno propio» no fue el fruto del consenso ni expresión de una eventual voluntad general, sino resultado de la imposición y el instrumento de «intereses creados» ${ }^{20}$ : «Todos sabemos, hoy, que el gobierno nació como un producto de la fuerza o de la astucia con que una minoría impuso su voluntad a una mayoría». Y, sin embargo, «cuando ya nadie acepta la teoría del contrato social [...] cuando ya

\footnotetext{
${ }^{17}$ Carlos Sánchez Viamonte, Derecho político (ensayos) (Buenos Aires: Sagitario, 1925).

${ }^{18}$ Sánchez Viamonte, Derecho político, 45.

${ }^{19}$ Sánchez Viamonte, Derecho político, 79.

${ }^{20}$ Sánchez Viamonte, Derecho político, 92.
} 
nadie cree en la generación espontánea y libre del gobierno dentro de la sociedad, todavía se rigen los países republicanos por el sistema de Rousseau y todavía se impone el principio teórico de 'pueblo'» ${ }^{21}$.

La segunda crítica de Sánchez Viamonte no era de carácter histórico, sino doctrinario, y remitía al carácter ilimitado que la soberanía confería al poder. Si bien su transferencia del rey al pueblo había significado un avance para la libertad, la soberanía del pueblo basada en la voluntad general rousseauniana, noción "artificial y falsa», «ficción contradictoria» y «esfuerzo metafísico» ${ }^{22}$, había tenido dos consecuencias. Por un lado, el fortalecimiento del estado: «El 'soberano pueblo' reemplazó en la teoría al 'soberano rey'; su voluntad general encarnó en el poder del Estado, y el Estado quedó siempre colocado en primer término, como un fin, como una finalidad ${ }^{23}$. En segundo lugar, la legitimación de la arbitrariedad: «iEl pueblo soberano sólo existe como ficción abstracta, cómoda de invocar para la legitimación de cualquier violencia de abajo o de arriba! ${ }^{24}$.

En tercer lugar, la soberanía del pueblo obturaba la representación, «que es casi todo el problema político» ${ }^{25}$. Así lo había planteado el propio Rousseau, al concebir indelegable la soberanía ${ }^{26}$. Sin embargo, el problema no terminaba allí. Las democracias liberales, a juicio de Sánchez Viamonte, en lugar de abandonar el concepto, habían procurado moderarlo e instrumentarlo, postulando un individuo «soberano», titular de una "parte alícuota de la soberanía», que se expresaba a través del sufragio: "Todos o casi todos los tratadistas de derecho político [...] admiten el sufragio como instrumento de soberanía, ejercido por los individuos $»^{27}$. Ahora bien, todo esto implicaba una distorsión:

la soberanía es una e indivisible, tanto en la doctrina de Rousseau como en la declaración de los derechos del hombre o en las constituciones francesas que le siguen, y no es posible admitir la afirmación inexplicable y contradictoria de que cada individuo

${ }^{21}$ Sánchez Viamonte, Derecho político, 146; también, 89-95. Cabe consignar la curiosidad de que el blanco principal de esta diatriba sea Rousseau, teniendo en cuenta los argumentos que éste había desplegado en el Discurso sobre el origen y los fundamentos de la desigualdad entre los hombres.

${ }^{22}$ Sánchez Viamonte, Derecho político, 46.

${ }^{23}$ Sánchez Viamonte, Derecho político, 145.

${ }^{24}$ Sánchez Viamonte, Derecho político, 148-149.

${ }^{25}$ Sánchez Viamonte, Derecho político, 150. Con las modulaciones propias aquí expuestas, Sánchez Viamonte contrapuso democracia a gobierno representativo, tópico usual en el debate público argentino de inicios del siglo XX. Cfr. Roldán, ed., Crear la democracia.

${ }^{26}$ Sánchez Viamonte, Derecho político, 81.

${ }^{27}$ Sánchez Viamonte, Derecho político, 44. 
contiene en sí mismo una partícula de la soberanía, pero no como hombre sino como miembro de la colectividad- Estado ${ }^{28}$.

En consecuencia, se amputaba o fragmentaba la soberanía, y «la expresión de la voluntad general» consistía en realidad en «una imposición coercitiva de determinados individuos, los electores» y así, en «una injusticia monstruosa»: «Esto no se llama democracia; se llama oligarquía». Inconsistencias similares (partir del «dogma de la indivisibilidad de la soberanía» y aceptar «desmembraciones del poder público») recorrían a la separación del poder o al federalismo ${ }^{29}$.

Las democracias liberales, en consecuencia, habían intentado impedir la «tiranía de las mayorías» introduciendo la representación, pero al hacerlo sin apartarse de la soberanía popular, culminaron siendo una «tiranía de las minorías». Y, vale aclarar, a juicio de Sánchez Viamonte esto era así no sólo porque las elites políticas legitimadas por el sufragio solieran gobernar para sus propios intereses, sino porque el mismo universo de electores, aun siendo cada vez más amplio, era una minoría: «El hecho indiscutiblemente cierto de hallarse la efectividad del poder público en manos de una mayoría del cuerpo electoral en todas las organizaciones democráticas, no nos impide admitir la existencia de fuerzas genuinamente sociales que actúan sobre la vida de las instituciones» ${ }^{30}$.

En suma, para Sánchez Viamonte la democracia liberal no era una síntesis virtuosa entre derechos individuales y soberanía popular, ni una idónea traducción política de la sociedad. Era una expresión de que «la estructura liberal republicana reposando sobre la ficción satisfactoria de la soberanía popular» no podía escapar a las consecuencias de esa «ficción», la arbitrariedad, derivada tanto de los atributos que otorgaba al poder como de las aporías que imponía a la representación. Por lo tanto, su vigencia sólo podía entenderse por haberse convertido en dogma:

Es tan hermosa la ideología revolucionaria de la democracia liberal y tan reconfortante su triunfo finalmente definitivo contra el absolutismo monárquico y la aristocracia feudal que, durante siglo y medio, casi, los pueblos occidentales convirtieron en dogma sus principios y en artículos de fe sus declaraciones ${ }^{31}$.

\footnotetext{
${ }^{28}$ Sánchez Viamonte, Derecho político, 47.

${ }^{29}$ Sánchez Viamonte, Derecho político, 50-51. Más en general: 20-39, 43-51. Entre los autores aludidos para apoyar estas argumentaciones aparecen Adolfo Posada, o John Stuart Mill, quien, según Sánchez Viamonte, "niega el carácter representativo al sufragio individual y al sufragio de la mayoría", 33.

${ }^{30}$ Sánchez Viamonte, Derecho político, 108.

${ }^{31}$ Sánchez Viamonte, Derecho político, 143-144.
} 
La forma de escapar al dilema, por lo tanto, no era transferir la soberanía a otro titular distinto al "pueblo», tal como lo proponía la teoría alemana de la soberanía del estado y su autolimitación a través de un régimen jurídico: «No advierto la claridad de las demostraciones alemanas que pretenden rectificar ideas oscurecidas por los franceses» ${ }^{32}$. La solución consistía en cambiar los fundamentos del poder público. Y esto significaba abandonar la soberanía y sustituirla por la noción de servicio público. Pues si el estado fuera concebido como mera «administración de intereses sociales [...] dejará de ser poder de mando, autoridad, imperio, y quedará lisa y simplemente, servicio público. Poner el Estado al servicio de la sociedad, ése es, en pocas palabras, el problema que debe resolverse técnicamente. El Estado no tiene fines, carece de sustantividad $»^{33}$.

Semejante noción del estado se apoyaba, como puede verse en esta misma cita, en una noción singular de sociedad. El individuo y sus derechos subjetivos «consagraban el más peligroso individualismo, dejando franca la puerta a la fuerza económica que produce la injusticia social» ${ }^{34}$. Los pilares de la sociedad debían ser los intereses, la función social y la cooperación: «La asociación cooperativa de todos los hombres útiles a la sociedad, agrupados por la afinidad de sus profesiones y oficios, parece ser la base orgánica del Estado futuro» ${ }^{35}$. Acudiendo a Duguit, apuntaba que

se define ya y se infiltra en la legislación de todos los países civilizados, como producto de intensa y aguda elaboración, un sistema jurídico que va desplazando a ojos vistas el antiguo sistema [...] Descansa en una concepción realista de la organización política y elimina poco a poco la metafísica del derecho subjetivo: es la noción de función social ${ }^{36}$.

El argumento central de Sánchez Viamonte, en síntesis, consistía en que soberanía, individualismo y democracia liberal habían sido principios y propuestas históricamente valiosos (por «limitar el abuso ejercido cons-

${ }^{32}$ Sánchez Viamonte, Derecho político, 89. Cita a Gerber y a Jellinek, también al suizo Bluntchsli, a lo largo del texto.

${ }^{33}$ Sánchez Viamonte, Derecho político, 151. Otro de sus argumentos contra la soberanía era precisamente que, fuera cual fuese el titular invocado, implicaba concebir al estado como una "personalidad sustantiva con voluntad de querer y mandar", 45.

${ }^{34}$ Sánchez Viamonte, Derecho político, 194. En el texto en el que está este pasaje desarrolla un argumento crítico de Kant. El texto se llama: "El ocaso de la libertad jurídica". También hay otro titulado: "El individualismo jurídico político de Kant". Cfr. Jorge Dotti, La letra gótica. Recepción de Kant en Argentina, desde el romanticismo hasta el treinta (Buenos Aires: Facultad de Filosofía y Letras, UBA, 1992).

${ }^{35}$ Sánchez Viamonte, Derecho político, 152.

${ }^{36}$ Sánchez Viamonte, Derecho político, 56. 
tantemente por los detentadores de la fuerza política» ${ }^{37}$ ), pero estaban en tensión entre sí (a pesar de su imbricación histórica), habían quedado obsoletos, y eran peligrosos. En lugar de la libertad que proclamaban, atentaban contra ella, suponían una imperfecta traducción política de la sociedad, y fundamentaban una perniciosa noción del estado ${ }^{38}$. Para lograr que «la libertad [pudiera] suceder a la autoridad $»^{39}$, era necesaria una reformulación jurídica en sintonía con las transformaciones sociales (una reelaboración del derecho atenta a la sociología), pautada por el abandono de la noción de soberanía, de individuo y de derecho, y su sustitución por la libertad entendida como solidaridad, y la sociedad como conjunto de intereses regulada por un estado sustentado en la noción de servicio público ${ }^{40}$.

\section{La soberanía según Faustino Legón}

Faustino Legón (1897-1959) fue uno de los juristas católicos más importantes en la Argentina de las décadas de 1920 a 1950. Fundador de los Cursos de Cultura Católica (espacio decisivo en la formación de intelectuales católicos en la Argentina de la primera mitad del siglo XX) y colaborador de Criterio, pionera y prestigiosa publicación del catolicismo argentino, fue el primer profesor titular de Derecho Político en la Universidad Nacional de la Plata (cargo que también desempeñó en la Universidad de Buenos Aires en la década de 1940), y ya en los años 1950, el primer Decano de la Facultad de Derecho de la Universidad Católica y miembro del Consejo Directivo de la Universidad del Salvador. Exponente de la reactivación del pensamiento católico (signado por el neotomismo) en la Argentina de entreguerras, la trayectoria de Legón se caracterizó por la intervención académica más que por la polémica política, y distó de contarse entre las voces más intransigentes. Aun así, fue funcionario del gobierno de Manuel Fresco en la provincia de Buenos Aires (conocido por sus simpatías con el fascismo), estuvo vinculado

${ }^{37}$ Sánchez Viamonte, Derecho político, 54.

${ }^{38}$ Sánchez Viamonte subrayaba que su posición no lo conducía a adherir a otras novedades de entonces críticas del liberalismo, como el fascismo o el socialismo soviético: Derecho político, 207-209.

${ }^{39}$ Sánchez Viamonte, Derecho político, 152.

${ }^{40}$ Años más tarde, Sánchez Viamonte volvió a tratar críticamente el problema de la soberanía, desde el derecho constitucional, en un estudio sobre el poder constituyente, en el que, por lo demás, se advierte su recepción y sus contrapuntos con Carl Schmitt. Cfr. Dotti, Carl Schmitt, 343-367. 
al gobierno de facto surgido del golpe de estado de 1943, y apoyó la reforma constitucional de $1949^{41}$.

Sus consideraciones sobre la soberanía estuvieron tamizadas por la postulación de la subordinación del poder político al religioso, por la revalidación del derecho natural frente al positivismo jurídico, y por una concepción natural y finalista del estado basada en la noción de bien común ${ }^{42}$.

Desde estas premisas, desplegó nociones críticas de la soberanía, a la que conectó con el liberalismo. La soberanía suponía una autonomía y una radical separación de lo político respecto de lo religioso, y, por lo tanto, el desconocimiento de una dimensión trascendente que debía guiar la acción del poder temporal. El liberalismo, a su turno, había diluido la finalidad del estado al colocar en el centro al individuo y sus fines, abriendo así la posibilidad de una disolución anarquizante de la sociedad: «Es cierto que, desde Locke, el liberalismo pugnó por mantener sin alienación los derechos individuales; pero si eso no se conecta con un derecho objetivo superior fracasa por la descomposición anárquica o cae en el inevitable estatismo paulatinamente interventor ${ }^{43}$.

Soberanía y liberalismo, positivismo jurídico y nociones «subjetivas» del derecho, eran así eslabones de una cadena que había absolutizado la política, y cuyas consecuencias eran el estatismo, el cesarismo o el totalitarismo:

No es exagerado afirmar que el incremento del Estado como forma superior y sintetizadora de la Sociedad pudo surgir de los propios postulados individualistas. Esta es su tragedia. El Estado moderno al confinar la religión a asunto privado viose [sic] sin filosofía propia sobre la cual basar la ética pública ${ }^{44}$.

Para Legón, la reinserción de los derechos individuales en el derecho natural, o la colocación de «lo supremo humano (la soberanía) bajo la

\footnotetext{
${ }^{41}$ Juan Fernando Segovia, "Faustino Legón: del Derecho Natural al Derecho Constitucional”, Anales de la Fundación Francisco Elías de Tejada XVII (2012); Raúl Arlotti, "Las primeras lecciones de Derecho Político del Profesor Titular Faustino J. Legón en la Facultad de Derecho y Ciencias Sociales de la UBA", en Facultad de Derecho y Ciencias Sociales. Enseñanzas de su historia, ed. Tulio Ortiz (Buenos Aires: Facultad de Derecho UBA, 2015); Arlotti, "Faustino Legón".

${ }^{42}$ Faustino Legón, Tratado de Derecho Político General (Buenos Aires, Ediar, 1959), T. I, 427-469. Legón se inscribió en las posiciones "personalistas" referenciadas con Jacques Maritain, en su momento objeto de críticas desde voces ortodoxas: "El fin del Estado es completar y dignificar la potencia de la personalidad humana" (T. I, p. 445). Respecto de las polémicas en torno a Maritain: T. I, 446-450, 558-566. Sobre la incidencia de Maritain en Legón, Segovia "Faustino Legón".

${ }^{43}$ Legón, Tratado, T. I, 341.

${ }^{44}$ Legón, Tratado, T. I, 497.
} 
dependencia de la verdadera supremacía: la de Dios y la ley natural», eran garantías imprescindibles para contrarrestar la arbitrariedad o el despotismo legados por el liberalismo, el positivismo jurídico y el poder soberano ${ }^{45}$. En sus propias palabras: «La concepción cristiana de la soberanía garantiza doctrinalmente al individuo contra la hipertrofia del Estado. Ubica eficazmente fuera y sobre la ciencia del gobernante y del súbdito el principio del poder. Intentos semejantes, sin la divinidad, resultan fracasos $»^{46}$.

Ahora bien, cabe decir que, de todos modos, Legón no desplegó una crítica frontal a la soberanía ${ }^{47}$. A su entender, resituándola en una distinción clara entre poder religioso y poder temporal, que dejara establecida la subordinación del segundo al primero, pero también la competencia de cada uno en sus respectivas dimensiones, la soberanía era un elemento clave para el poder político: «Fuera del bien público temporal el Estado no es soberano porque no es competente. De modo que los límites de la soberanía están determinados por el ámbito de los fines del Estado» ${ }^{48}$.

Desde esta perspectiva, Legón se distanció de las objeciones sustantivas a la soberanía. Entre ellas, las que integraban la «corriente pluralista sociológico-legal» ${ }^{49}$, entre quienes incluía (junto a nombres como el de Harold Laski), a León Duguit, «obsesionado por su anhelo de sustituir el concepto de 'mando' por el de 'servicio'» ${ }^{50}$. A éstas atribuía un «influjo aceptable», la búsqueda de una «una limitación en las finalidades del estado». Pero discrepaba con «su negación latente de la soberanía política» y entendía que «sólo un abuso terminológico podría permitir el postulado de una pluralidad de soberanías» ${ }^{51}$. Asimismo, expresó contrapuntos con autores católicos, entre ellos uno que constituyó una referencia a largo de su obra, Jacques Maritain,

\footnotetext{
${ }^{45}$ Segovia, “Legón", 106.

${ }^{46}$ Legón, Cuestiones de política, 75.

${ }^{47}$ Puede decirse que su posición se matizó a lo largo de su obra. Un texto más temprano es de tono crítico mientras que su tratado, como enseguida se verá, reconoce mayores matices en el abordaje del tema. Faustino Legón, La soberanía: conceptos, formación histórica, doctrinas críticas, sentido ético (Buenos Aires: Librería Jurídica V. Abeledo, 1938); también: Faustino Legón, Cuestiones de política y derecho (Buenos Aires: Perrot, 1951), 39-79.

${ }^{48}$ Faustino Legón, Tratado de Derecho Político General (Buenos Aires: Ediar, 1961), T. II, 243. Legón discutió además la originalidad de la noción moderna de soberanía al cotejarla con la "aristotélica-escolástica" de "perfección": Legón, Tratado, T. II, 201-215. Véase Fernando Segovia, "El derecho entre iusnaturalismo, decisionismo y personalismo. Arturo Sampay lector de Carl Schmitt", Anales de la Fundación Francisco Elías de Tejada XX (2015).

${ }^{49}$ Legón, Tratado, T. II, 232.

${ }^{50}$ Legón, Tratado, T. II, 238.

${ }^{51}$ Legón, Tratado, T. II, 234-235.
} 
quien, «aunque con puntos de partida diferentes [...] coincide mucho con las conclusiones prácticas de Duguit y de Laski». Según Legón, la afirmación de Maritain de que

los dos conceptos de soberanía y absolutismo fueron "forjados juntos sobre el mismo yunque; los dos deben ser pulverizados juntos" es una conclusión exagerada, pues con no imposibles esclarecimientos y atemperaciones, puede subsistir digna y ventajosamente la atribución de soberanía al poder del Estado ${ }^{52}$.

El argumento de Legón (siguiendo a Carré de Malberg) era que debía distinguirse entre la soberanía del estado, las potestades del estado y la soberanía en el estado. Esta última aludía a qué agente humano era titular de la soberanía, y la segunda era polémica, porque podía conducir a una confusión entre soberanía y poder. La soberanía era un concepto de «naturaleza puramente formal $»^{53}$, una «cualidad» o una propiedad, vinculada a una posición «eminente». Por todo ello, la noción «soberanía del estado» permitía otorgarle al concepto precisión jurídica. Pues remitía a la «capacidad legal» (tal como había postulado Jellinek), y esto era adecuado porque: «toda capacidad está en relación estricta con el fin o el destino de la personalidad que la sustenta». La capacidad del estado (y sólo del estado - de allí su afirmación de que quienes postulaban una pluralidad de soberanías a causa de la diversificación de la sociedad cometían un «abuso terminológico»-) consistía en definir un régimen jurídico en el orden temporal. Había una asociación indisoluble entre estado, soberanía y derecho ${ }^{54}$.

No obstante, Legón no adhirió a una noción exclusivamente jurídica de soberanía. De hecho, criticó la teoría de la soberanía estatal y de la autolimitación. Esta crítica se apoyó en argumentos ya señalados: dicha teoría implicaba una autonomía radical de lo político, una «simbiosis de lo ético y lo jurídico», y fundamentaba así un positivismo jurídico potencialmente arbitrario: «Por mucho que quiera evitarse el riesgo [del «absolutismo»] haciendo soberano el Estado [sic], su actividad se manifiesta a través de voluntades humanas incontrolables. La ambición de frenar el Estado con el Derecho es irrealizable, si no se admite un origen del derecho que sea superior al Estado mismo» ${ }^{55}$. Por ende: «Un dique sólido se eleva contra los eventuales excesos

\footnotetext{
${ }^{52}$ Legón, Tratado, T. II, 239-241.

${ }^{53}$ Legón, Tratado, T. II, 214.

${ }^{54}$ Legón, Tratado, T. II, 197-198.

${ }^{55}$ La teoría de la autolimitación estatal era parte "del círculo vicioso de la inmanencia humana de la autoridad". Legón, Cuestiones de política, 76-77.
} 
de los gobernantes si se reconoce como regla absoluta, rigurosa, inflexible la sumisión del Estado al Derecho natural, y aun a las prescripciones de la ley positiva que traducen las eternas pautas de aquél» ${ }^{56}$.

Su distanciamiento de una idea plenamente jurídica de soberanía se basaba en una segunda razón: el estado, en su (subordinada) área de competencia, debía tener poder de decisión. Es decir, era clave reconocer que la soberanía debía tener una dimensión política:

La idea de una soberanía política que en el orden político auténtico sea decisiva para la función arbitral en el conflicto de los intereses encontrados de los grupos es incancelable [sic]: la misión irreductible del Estado es la de orientar, contener, amparar; es su misma razón de ser [...] la decisión que domina la cúspide -aunque esté bien ceñida o limitada a sus fines- es políticamente la soberana; y de ella no cabe prescindir ${ }^{57}$.

Y en este sentido, y sin desconocer las potencialidades despóticas que sobre todo recorrían a su versión rousseauniana, el depósito idóneo para la soberanía política era el pueblo:

La 'soberanía del pueblo' por algunas de sus implicancias filosóficas y por no pocas de sus deplorables aplicaciones tumultuarias concitó oposiciones profundas y condenas [...] El pueblo aparecería negando, sustituyendo a la divinidad. Pero tal interpretación no es la más obvia en el campo político. Sólo cabría si implicase un desconocimiento de la causa primera; no, si apenas aludiese a las causas segundas, en lo que corresponde al derecho humano. La extremosidad herética también puede enrostrarse al autocratismo o a las monarquías absolutas, cuando de manera equivalente pretenden suprimir o suplantar a Dios. Estrictamente ubicado el asunto en la zona de la organización humana de las potestades correctas, se disipan algunos equívocos, se destruyen ciertas suposiciones exageradas y belicosas. Entonces de condenable pasa a ser plausible el afán de otorgar soberanía al pueblo mismo, comparado al ímpetu que tiende a la soberanía del autócrata. Pierden eficacia y mordacidad las expresiones agresivas y destempladas, como las de considerar la soberanía del pueblo "concepto infantil, ridícula, injusta e inmoral" ${ }^{\prime 2}$.

${ }^{56}$ Legón, Tratado, T. I, 347.

${ }^{57}$ Legón, Tratado, T. II, 234-235. Este reconocimiento de la decisión política, vale aclarar, no suponía adhesión al decisionismo de Carl Schmitt, pues en éste había una noción de soberanía -como decisión en el estado de excepción- que era expresión de una radical absolutización de lo político. Aun así, cabe mencionar que Legón, además de referir la estatura del jurista alemán como crítico del liberalismo, en otros temas moderó sus contrapuntos con él: Dotti, Carl Schmitt, 171-184.

${ }^{58}$ Legón, Tratado, T. II, 224-225. Como se dijo, en otros textos su tesitura había sido más crítica, al poner en equivalencia la "Idolatría de la muchedumbre o del César: ambos extremos ponen el absolutismo en la raíz de la gobernación», aludiendo a De Bonald para desdeñar "la soberanía atea que es origen de rebeldía, causa de caos y motivo, en definitiva, de opresión". Cuestiones de política, 76, 78. 
En síntesis, la soberanía era un rasgo político necesario del estado, cuyo depósito debía ser el pueblo, siempre y cuando no se olvidara el marco general, una subordinación de lo político a lo religioso, o, en todo caso, del derecho positivo al derecho natural, y un estado entendido como «natural» y orientado a una finalidad, el «bien común». Tales aspectos eran fundamentales para impedir una absolutización y una inmanencia de la política que condujera al despotismo o a la anarquía: «el Estado es soberano y debe contar con la energía necesaria para la decisión final en los asuntos, no cualesquiera sino los que le competen. De ahí el maridaje, la íntima trabazón entre soberanía, bien común y libertad» ${ }^{59}$.

\section{La soberanía en José Bianco y Mariano de Vedia y Mitre}

José Bianco fue una figura importante del reformismo universitario en La Plata. Se destacó por sus críticas a la «oligarquía universitaria» representada por académicos e intelectuales de importancia en la Argentina de inicios del siglo XX, como Joaquín V. González o los hermanos Rivarola ${ }^{60}$. Vinculado al radicalismo (fue corresponsal de confianza, en especial en los años treinta, de Marcelo T. de Alvear), Bianco estuvo a cargo de un curso de derecho político denominado Historia de las Instituciones Representativas desde 1915, que publicó con el título Vida de las instituciones políticas.

En ese texto, Bianco expone, entre otros argumentos, una ponderación del liberalismo anglosajón, en la que sobresale el señalamiento de la ausencia de la soberanía en esa tradición (a diferencia de la continental) y la relación de correspondencia entre esa ausencia y el avance de la libertad. En la historia inglesa, de la Carta Magna en adelante, «no aparece nunca el concepto de soberanía». Fue, en cambio, con la Revolución Francesa, que éste se

${ }^{59}$ Legón, Tratado, T. II, 242. Los lineamientos de Legón tienen puntos en común con las consideraciones que acerca de la soberanía volcó uno de sus discípulos más notorios, Arturo Sampay, jurista de gravitación en la reforma constitucional de 1949. En Sampay, sin embargo, puede identificarse una crítica más estructural, al definir literalmente a la soberanía como "falsa". Las consideraciones de Legón sobre la soberanía (y sobre el liberalismo), pueden conectarse, asimismo, con las que formulara otro notorio jurista católico del período, Tomás Casares, quien fue presidente de la Suprema Corte de Justicia argentina en los años 1940. Cfr. Ignacio Lucero, "La filosofía del derecho del Dr. Tomás Casares", Cuyo 12 (1979). Sobre Sampay: Fernando Segovia, "El derecho entre iusnaturalismo"; Dotti, Carl Schmitt, 135-166.

${ }^{60}$ Pablo Buchbinder, Historia de las universidades argentinas (Buenos Aires: Sudamericana, 2005), 102-104. 
«universaliza ${ }^{61}$. Esos caminos distintos habían entramado, en Inglaterra, un aprendizaje «práctico» de la libertad, diferente a las proclamaciones doctrinarias de los «pueblos latinos»: «el pueblo inglés [...] se despreocupaba en absoluto del concepto doctrinario, para conquistar la práctica de la libertad en todas sus manifestaciones». En segundo lugar, tales itinerarios habían promovido un papel y un lugar diferente para el estado. En los «pueblos latinos» era anhelada «la tutela del estado» sin advertir que «esa tutela [...] restringe la libertad». Según Bianco, había una «antítesis entre la independencia individual y la tutela del estado» ${ }^{62}$.

Así, afirmó que «la omnipotencia del estado [es] suprema negación de la libertad individual» ${ }^{63}$. Y, más aun: «La omnipotencia del estado, que unifica todos los poderes, es tan arbitraria como la omnipotencia que encarna el valor numérico de las multitudes. Entre la omnipotencia denominada popular y la omnipotencia apellidada poder absoluto, existe una relación de equivalencia» ${ }^{64}$.

Cabe consignar, de todos modos, que estas afirmaciones no concluían en un repudio a la democracia en nombre de la libertad. Para Bianco, la «soberanía del pueblo» era un principio afirmado en las sociedades de su tiempo, y el sufragio, en expansión, el instrumento que «substantiva la soberanía del pueblo en la organización política ${ }^{65}$. La democracia no significaba necesariamente disolución de jerarquías ni caudillismos autoritarios. Era, en cambio, una forma de sociedad y de régimen político capaz de depurar sus propios peligros o problemas, pues reconocía «el esfuerzo que dignifica», generaba elites legítimas, y consagraba a través de la representación a sus mejores exponentes ${ }^{66}$.

A juicio del profesor de la Universidad de La Plata, la democracia evitaba que la «soberanía del pueblo» condujera a «la omnipotencia de las

${ }^{61}$ Bianco, Vida, 89.

62 Bianco, Vida, 108.

${ }^{63}$ Bianco, Vida, 312. La frase parece remitir a un texto de Juan Bautista Alberdi, referente del liberalismo argentino: "La omnipotencia del estado es la negación de la libertad individual”, en Obras completas (Buenos Aires: La Tribuna Nacional, 1887) T. VIII, 157-182.

${ }^{64}$ Bianco, Vida, 318.

${ }^{65}$ Bianco, Vida, 90.

${ }^{66}$ Bianco, Vida, 51-53, 301-302. Para Bianco no había contraposición entre democracia y gobierno representativo, tanto porque la representación no distorsionaba o atenuaba la democracia, como porque la representación no debía sustentarse en principios diferentes a la soberanía del pueblo. Podría decirse que una lectura elitista -o, más matizadamente, meritocrática- de la democracia informaba el liberalismo de Bianco y lo conducía a confiar en que la democracia conciliara igualdad y libertad. 
multitudes», a través de la representación, del ejercicio del sufragio, y de su potencialidad para corregirse a sí misma. Y era un antídoto a los abusos del poder constituido, pues «el gobierno del pueblo es una divisa que elimina la fraseología con que siempre se han amparado las autoridades constituidas, al pretender cohonestar, con la legalidad mecánica, las arbitrariedades y las prepotencias del poder» ${ }^{67}$.

En suma, Bianco muestra una modulación liberal cautelosa frente a la democracia, pero no de rechazo franco, derivada a su vez de la consideración de su irreversibilidad histórica, así como de su indeterminación política. Estos tópicos lo ubican en una zona del liberalismo argentino poco explorada por la historiografía, que ha destacado, fundamentalmente, sus torsiones conservadoras y antidemocráticas ${ }^{68}$. $Y$, vale destacar, el señalamiento de una democracia en expansión, visible por cierto en otros textos contemporáneos ${ }^{69}$, indica cuán imperceptible podía resultar para testigos de entonces la crisis de la democracia liberal en los años de la primera posguerra.

Más allá de esto último, en lo referido a la soberanía, el texto de Bianco podría filiarse con el liberalismo clásico ${ }^{70}$, por su consideración de que la libertad encuentra en ella una amenaza, en tanto habilita «omnipotencias», en especial del estado. Como se apuntó, refirió elogiosamente al último Alberdi, al que, en otro de sus libros, consideró «su maestro por más de treinta años» ${ }^{71}$.

Para Bianco, liberalismo y soberanía no eran parte de una misma tradición, sino principios en tensión. A su juicio, además, la limitación del poder del gobierno no era una solución para garantizar la libertad, sea porque era en sí difícil (la distinción funcional no suponía en la práctica una real división o distribución del poder ${ }^{72}$ ); sea porque, para Bianco, no había diferencias

\footnotetext{
${ }^{67}$ Bianco, Vida, 158.

${ }^{68}$ Losada, "Liberalismo y derechas"; María Inés Tato, Viento de fronda. Liberalismo, conservadurismo y democracia en la Argentina, 1911-1932 (Buenos Aires: Sudamericana, 2004); Jorge Nállim, Transformación y crisis del liberalismo. Su desarrollo en la Argentina en el período 1930-1955 (Buenos Aires: Gedisa, 2014).

${ }^{69}$ Cfr. Norberto Piñero, Política. El momento presente. Problemas sociales y políticos. Estabilidad de la constitución (Buenos Aires: Menéndez, 1929).

${ }^{70}$ Ezequiel Gallo, Vida, libertad, propiedad. Reflexiones sobre el liberalismo clásico y la historia (Caseros: Untref, 2008).

${ }^{71}$ José Bianco, Mis lecturas (Buenos Aires: Librería Mendensky- Augusto Sabourin e hijo, 1920) 197.

${ }^{72}$ Según Bianco: "las tres fases fundamentales del poder: la voluntad que legisla, la voluntad que ejecuta y la voluntad que juzga. Estas fases concretan la división tripartita del poder, doctrinariamente aceptada por la ciencia política, sin recordar que, en resumen, como síntesis orgánica, sólo existe un poder único, al unificarse todas las fuerzas que elaboran la organización política". Vida, 119.
} 
sustantivas entre estado y gobierno, entre poder político y soberanía, ya que «el estado se exterioriza en el gobierno». De allí que, a su juicio, el antídoto más eficaz contra la arbitrariedad no radicara en la división del poder sino en nombre de quién se ejercía. Y al respecto, el fundamento democrático era la mejor opción ${ }^{73}$.

En este marco, merecen introducirse las consideraciones que dejó acerca de la soberanía, y de sus relaciones con la libertad, Mariano de Vedia y Mitre. Intendente de la ciudad de Buenos Aires entre 1932 y 1938, fue el primer profesor titular de Derecho Político de la Universidad de Buenos Aires, desde 1924 hasta 1946.

De Vedia entendió que la soberanía era fundamental para la libertad. Esta afirmación se apoyó en tres argumentos principales: la crítica a nociones políticas de la soberanía, entre ellas, la del pueblo; la adhesión a una definición jurídica, tal como la había planteado la teoría alemana de la autolimitación estatal; y la distinción entre poder y soberanía, entre gobierno y estado.

La crítica a la soberanía del pueblo osciló entre una impugnación a su implementación, y una refutación sustantiva. A juicio de De Vedia, podía decirse que la soberanía del pueblo había jugado un papel en la historia de la libertad al emerger como principio opuesto a la soberanía monárquica. Pero había conducido, a través de lo que llamó la «delegación» de la soberanía, a tiranías y despotismos. Estas consecuencias, en principio adjudicadas a quienes habían volcado a la política real la aplicación del concepto, culminaron promoviendo en De Vedia un juicio categórico acerca de la noción misma $^{74}$. Tal como planteó en una de las últimas ediciones de su Derecho Político General, la soberanía del pueblo «no es en manera alguna admisible ante el más simple análisis del problema» ${ }^{75}$.

Semejantes consideraciones, sin embargo, no decantaron en una crítica a la soberanía, o en una oposición entre ésta y la libertad (como podía leerse en Sánchez Viamonte o el propio Bianco). Por el contrario, De Vedia desarrolló una reelaboración del concepto, precisando cuál debía ser su titular y cuál su sentido genuino. Para semejante tarea, se apoyó en los lineamientos planteados por Jellinek, Ihering y otros. Es decir, en la teoría de la soberanía estatal y autolimitada.

\footnotetext{
${ }^{73}$ Bianco, Vida, 88.

${ }^{74}$ Mariano de Vedia y Mitre, Curso de Derecho Político (Buenos Aires: Biblioteca Jurídica, 1934), T. 1, 91-100, 113-117, 136-141.

${ }^{75}$ Mariano de Vedia y Mitre, Derecho Político General (Buenos Aires: Kraft, 1952), T. II, 358.
} 
Según De Vedia: «El estado es una persona moral, sujeto de derecho con poder coactivo; está dotado por tanto de unidad, y se halla formado por una comunidad humana asentada con ánimo de permanencia en un territorio determinado y cuyo atributo esencial es la soberanía» ${ }^{76}$. La soberanía del estado no implicaba arbitrariedad, porque su ejercicio se plasmaba en la creación de un régimen jurídico: «el Estado no es omnipotente; y si hay una regla de derecho ésta es de tal importancia y de tal alcance que comprende al mismo Estado» ${ }^{77}$. El estado está «lógicamente sometido al derecho». Es un régimen jurídico, o no es estado. Por ello, «la soberanía es sobre todo y ante todo un concepto jurídico» ${ }^{78}$.

El carácter soberano, entonces, se expresaba en una autolimitación voluntaria, artífice de un régimen jurídico, que consagraba y garantizaba las libertades individuales. La autolimitación revelaba la soberanía (pues la limitación era voluntaria) y la estatura del estado como estado de derecho: «el régimen de derecho significa el propio sometimiento del poder del estado a las leyes que él mismo dicta» ${ }^{79}$.

Desde estas perspectivas, De Vedia no sólo adscribió a la teoría de la autolimitación estatal, sino que fustigó a los críticos de la soberanía, así como a los objetores del positivismo jurídico. Discutió las afirmaciones que planteaban que una soberanía limitada no era propiamente soberanía, o las dirigidas a la teoría de la autolimitación estatal. Uno de los destinatarios de estas críticas fue Duguit, a quien rebatió apoyándose en autores como Jellinek o Ihering. Según De Vedia, Duguit planteaba que «es inadmisible decir que el Estado tiene poder de coacción desde que él mismo está sometido al derecho». Frente a ello, refería que Ihering afirmaba

que la soberanía de que el Estado goza es de tal naturaleza que el Estado puede, como lo hace, autolimitarse [...] Duguit observa todavía que si existe esa limitación es porque hay una voluntad externa que compele al Estado. Esa voluntad es el derecho; y entonces el Estado habrá dejado de ser soberano y absoluto. Ihering contesta victoriosamente al afirmar que en virtud del régimen de derecho que es la característica del Estado, éste ha adquirido una conciencia jurídica que lo lleva a fundar aquel régimen de derecho en principios superiores que descartan toda arbitrariedad ${ }^{80}$.

${ }^{76}$ De Vedia y Mitre, Derecho Político, T. II, 473.

${ }^{77}$ De Vedia y Mitre, Curso, T. I, 76-77.

${ }^{78}$ De Vedia y Mitre, Derecho Político, T. II, 449; también Curso, T. I, 7-44.

${ }^{79}$ De Vedia y Mitre, Derecho Político, T. II, 450.

${ }^{80}$ De Vedia y Mitre, Curso, T. I, 80-81. Cfr. también: 136-141; De Vedia y Mitre, Derecho Político, T. II, 331-334, 373-378, 427-434. Formuló críticas similares a Posada: Derecho Político, T. II, 451-453. Sobre Duguit y Posada, Curso, T. I, 95-100. 
De Vedia afirmó que el «derecho objetivo» del estado no podía ser arbitrario, y que, por ende, no había una contradicción entre derecho positivo y derechos subjetivos o individuales: «No hay conflicto entre el derecho subjetivo de la personalidad humana y el derecho positivo de la personalidad del Estado» ${ }^{81}$.

En esta dirección, rebatió el iusnaturalismo: «el derecho natural no ha resistido a la crítica filosófica [...] El derecho existe en potencia, diríamos, aunque el Estado no lo declare, pero el régimen de derecho está formado exclusivamente por el derecho objetivo» ${ }^{82}$. Y planteó reservas frente al pensamiento de Tomás de Aquino, al apuntar que en sus obras «campea un poco la incoherencia, la falta de relación precisa entre unas y otras, la contradicción en la fundamentación de las instituciones», así como entendió, en una afirmación que indica su discrepancia con el neotomismo, que la distinción entre ley eterna, ley natural, ley humana y ley divina era improcedente: «esta clasificación de la ley [...] probablemente no entraría en una clasificación actual que hiciera de la ley, aun por aquellos espíritus más profundamente religiosos» ${ }^{83}$.

Por ende, no sorprende que haya polemizado con Faustino Legón, especialmente por la desestimación que éste hizo de la teoría de la autolimitación estatal: «Dice [...] que suponer la limitación del Estado 'por su propia voluntad es fiar una engañifa'. Sin embargo, todo Estado de Derecho ha limitado por su propia voluntad su radio de acción; ha reconocido derechos a la personalidad humana que él mismo no puede ultrapasar» ${ }^{84}$.

Todo lo anterior, a su vez, coexistió con una concepción particular de la tradición liberal. En primer lugar, discrepó con el «liberalismo individualista», pues abogaba «por la limitación de las intervenciones del Estado en la vida de los ciudadanos. Pero esas soluciones demasiado sencillas basadas en la confianza del esfuerzo individual no respondían a la complejidad de los hechos» ${ }^{85}$.

Junto a lo anterior, revalidó a quienes habían promovido instrumentos e ideas para contener el poder. Esta galería de autores incluía figuras que trascendían el liberalismo, como Polibio y Maquiavelo, junto a Locke, Montesquieu y los federalistas norteamericanos; y, por ende, doctrinas también

${ }^{81}$ De Vedia y Mitre, Derecho Político, T. II, 198.

${ }^{82}$ De Vedia y Mitre, Curso, T. I, 74-75.

${ }^{83}$ De Vedia y Mitre, Curso, T. I, 233-234.

${ }^{84}$ De Vedia y Mitre, Derecho Político, T. II, 396-397. Las críticas de Legón a los objetores de la soberanía popular tenían a su vez como destinatario a De Vedia y Mitre.

${ }^{85}$ Mariano De Vedia y Mitre, Historia general de las ideas políticas (Buenos Aires: Kraft, 1946), T. X, 277-278. 
distintas, desde el gobierno mixto a la separación del poder, pasando por los frenos y contrapesos (formulaciones que De Vedia no confundió o asimiló).

El punto a destacar aquí es que para De Vedia era válida la distinción entre soberanía y poder, entre estado y gobierno. Esta tesitura lo llevó a criticar a los teóricos de la soberanía que entendían, a su juicio, que limitar el poder implicaba limitar la soberanía. Y a precisar, por otro lado, que el poder, y su expresión institucional, el gobierno, no eran soberanos: «una cosa es detentar el poder y otra ser titular de la soberanía ${ }^{86}$.

Así, si De Vedia destacó que la soberanía era indivisible, sí subrayó la posibilidad y la conveniencia de la división del poder. Era posible realizar una crítica del poder que no implicara una crítica de la soberanía. Incluso, como ya se vio, era posible una crítica a las soberanías «políticas» en nombre de una concepción jurídica. La distinción entre poder y soberanía permitía vigilar el poder constituido (y sus peligros eventuales, el despotismo), al esclarecer que quienes ejercían la soberanía no eran titulares de ella. Sin embargo, la crítica al poder no condujo a De Vedia a una crítica a la soberanía ${ }^{87}$.

Por último, De Vedia trazó apreciaciones singulares sobre los principales referentes del liberalismo argentino, entre ellos, Juan Bautista Alberdi. De hecho, De Vedia cuestionó el texto parafraseado por Bianco, La omnipotencia del estado es la negación de la libertad individual:

La omnipotencia del Estado es una realidad dentro del sistema constitucional que Alberdi contribuyó tan eficazmente a fundar, pero ella no gravita sobre la libertad individual. Si el Estado tiene derechos sobre la población correlativos a su poder, los derechos de la personalidad humana no son una ficción sino una realidad [...] Los abusos de poder son siempre posibles, pero para que puedan realizarse es necesario que deje de ser un Estado de derecho. Alberdi dice que la omnipotencia del Estado tiene por consecuencia necesaria la omnipotencia del gobierno en que el Estado se personifica. Ello no es exacto cuando una Constitución escrita y erigida como la Constitución argentina, fija los límites del poder del gobernante. Para la Constitución, si el Estado es omnipotente no lo son los gobernantes ${ }^{88}$.

Las críticas de De Vedia a Alberdi exponen los argumentos que desarrolló a través de la enseñanza del derecho político: no debía confundirse

${ }^{86}$ De Vedia y Mitre, Curso, T. I, nota al pie, 110; 77-78, 88-89; De Vedia y Mitre, Derecho Político, T. II, 272-341.

${ }^{87}$ Vale apuntar que a lo largo de la obra de De Vedia no se advierten referencias ni alusiones a Carl Schmitt, rasgo destacable en tanto constituía uno de los críticos más notorios de la tradición jurídica alemana que recuperó De Vedia y Mitre. Tampoco hay alusiones a la obra de Sampay, que para el momento de la publicación de la última edición de su derecho político general, era un jurista reconocido y referente de la Constitución de 1949.

${ }^{88}$ De Vedia y Mitre, Historia general, T. XIII, 168. 
soberanía y poder, estado y gobierno. Un estado era un estado de derecho o no era un estado. La soberanía del estado, de naturaleza jurídica más que política, por ello plasmada en la afirmación de un régimen jurídico y desde allí, en la legislación positiva, era condición de libertad y no de arbitrariedad.

\section{Conclusiones}

Las consideraciones sobre la soberanía desplegadas por cuatro profesores de Derecho Político en la Argentina de las décadas de 1910 a 1940, remiten a una variedad de temas y problemas cuyo tratamiento exhaustivo excede los límites de este trabajo. La reflexión sobre la soberanía alentó, o se proyectó, en argumentos relativos al derecho constitucional y al derecho político, a la confrontación entre positivismo jurídico y derecho natural, a la relación entre moral, justicia y derecho, a la evaluación de la democracia y de su sustento doctrinario en la soberanía del pueblo, o a las formas más pertinentes de expresar políticamente a la sociedad. Tal como se anticipó al inicio de este trabajo, el recorte propuesto aquí es de otro tenor: qué sugieren las reflexiones sobre la soberanía acerca de las ideas políticas del período, y especialmente, del liberalismo.

En primer lugar, vale subrayar que los casos aquí analizados muestran la recepción y la discusión de las teorías y autores más importantes acerca del tema en ese entonces. Nombres como Ihering, Jellinek, Gerber, Carré de Malberg, Duguit, Posada, Orlando, Maritain, Laski, Kelsen o Schmitt (estos últimos hacia el final del período) se reiteran en los textos aquí abordados, ciertamente con discrepancias en sistematicidad y en erudición (así como en adhesión o crítica). No todos estos autores, desde ya, eran novedades de la época, pues algunos eran conocidos al menos desde inicios del siglo XX (como Carré de Malberg, Bluntschli o Jellinek). Pero no parece desatinado afirmar, como después de todo lo testimoniaron los contemporáneos al apuntar la actualización y profundización de lecturas que exigió la apertura de las cátedras de Derecho Político, que este nuevo espacio de la enseñanza universitaria estimuló una reflexión política con anclaje jurídico, que se irradió en la progresiva delimitación de otras áreas del conocimiento, como la historia de las ideas políticas.

Paralelamente, los autores aquí tratados polemizaron entre sí, un indicador adicional de que se configuró un escenario que no cabe retratar como un ámbito académico desapasionado, sino que sirvió de plataforma, y fue caja de resonancia, de las discusiones políticas y doctrinarias de la época. De 
hecho, los cambios políticos ocurridos en el país afectaron los cargos académicos de algunos de ellos. Por ejemplo, Legón sustituyó a De Vedia y Mitre en la titularidad de Derecho Político de la UBA luego de su renuncia en 1947.

En segundo lugar, lo visto en las páginas anteriores revela que la crítica a la soberanía fue una de las maneras que asumió, al menos en el campo específico y restringido del Derecho Político enseñado en sede universitaria, la crítica al liberalismo. Y esa crítica tenía un sentido definido: había pergeñado un poder público opresivo, arbitrario, que había trasvasado sus límites legítimos de desempeño, o que, en el mejor de los casos, estaba desacompasado con las necesidades o características de la sociedad (tales tópicos, desde prismas particulares e incluso opuestos, fueron desplegados por Sánchez Viamonte o Legón).

Importa entonces resaltar un acento. En este tipo de formulaciones, junto a, o incluso más que, la «impotencia» liberal (es decir, la difuminación de lo político en favor de lo jurídico, tema central de la época, sobre todo en los debates de la Alemania de Weimar ${ }^{89}$ ), uno de los ejes más recurrentes al rebatir al liberalismo fue la prepotencia que le otorgaba al poder por no haber abandonado la noción de soberanía (a pesar de haberla criticado o procurado moderarla), o por sus propias aporías o inconsistencias.

Éstas eran, por ejemplo, invocar un principio de por sí «metafísico» como la soberanía del pueblo e instrumentarlo con fórmulas que, diciendo aplicarlo, lo contradecían o distorsionaban; u olvidar una dimensión normativa trascendente, que conducía a un subjetivismo en última instancia anarquizante o relativista que sólo podía resolverse con despotismo ${ }^{90}$. La posibilidad totalitaria, desde estos argumentos, no era el resultado de una confrontación externa al liberalismo, sino consecuencia de su propio despliegue. Semejantes críticas al estado liberal basado en la soberanía no conducían a promover, necesariamente, una retracción del poder público en la sociedad. La propuesta más usual fue, en cambio, modificar los principios que lo sustentaban, para que incluso su papel se fortaleciera (fuera el servicio público o el bien común).

Más allá de esto, un último punto a destacar es que la asociación establecida por los críticos del liberalismo entre éste y la soberanía (y desde allí,

${ }^{89}$ Cfr. Ellen Kennedy, Carl Schmitt en la República de Weimar. La quiebra de una constitución (Madrid: Tecnos, 2012).

${ }^{90}$ La crítica a la teoría de la autolimitación estatal abrevó en los mismos énfasis: era un "artificio" que prolongaba nociones metafísicas del accionar del poder público, cuya consecuencia era, más que la impotencia o la incapacidad para afrontar situaciones de crisis, la arbitrariedad. 
la arbitrariedad del poder) es llamativa teniendo en cuenta que la relación entre liberalismo y soberanía era un tema objeto de controversia, discutido hacia el interior del pensamiento liberal local (y desde ya, no sólo local). Los contrapuntos acerca de la relación entre soberanía y libertad entre Bianco y De Vedia y Mitre son un ejemplo modesto pero revelador, que podrían incluso desagregarse en una capa adicional: la aceptación de la soberanía del pueblo en Bianco y su crítica en De Vedia, en oposición a la ponderación de la soberanía estatal en De Vedia frente a las reservas a la omnipotencia estatal en Bianco. Contrastes que indican otro punto, el cual, por evidente, no merece perderse de vista, la pluralidad de visiones al interior del liberalismo acerca de la democracia y del estado. De hecho, la crítica a la soberanía del pueblo y la valoración positiva de la democracia no se consideraron argumentos excluyentes o recíprocamente contradictorios, como lo muestran De Vedia y Mitre y Sánchez Viamonte, tan distintos entre sí en sus posiciones políticas.

Ahora bien, las controversias acerca de la relación entre soberanía y libertad entre intelectuales liberales, o la crítica a la soberanía como modo de crítica al liberalismo, son comprensibles si se tienen en cuenta algunos rasgos de largo plazo del liberalismo argentino. Precisamente, que careció, desde sus mismos orígenes en el siglo XIX, de una reflexión crítica de la soberanía, y que, sobre ello, promovió un papel relevante del estado en la sociedad (lo cual, en materia constitucional, condujo a que tuviera más gravitación la discusión sobre el poder que sobre los derechos ${ }^{91}$ ).

Desde este punto de vista, los argumentos de De Vedia acerca de la pertinencia de la distinción entre poder y soberanía (que permitía concebir un estado soberano sin asociarlo a la arbitrariedad y al mismo tiempo mantener una tesitura vigilante frente a los excesos del gobierno) y su filiación con la teoría de la autolimitación estatal de procedencia alemana, son relevantes por dos razones.

En primer lugar, por lo ya dicho: exponen una tesitura de la reflexión liberal local que, situada en el largo plazo, revela continuidades en un modo de pensar la relación entre estado y sociedad, coexistentes, sin embargo, con críticas a algunos de los «padres fundadores», como Alberdi, y cimentada en referencias teóricas y doctrinarias que atestiguaban las reformulaciones ocurridas en el liberalismo de otras latitudes desde mediados del siglo XIX.

${ }^{91}$ Zimmermann, "Constitucionalismo argentino"; Darío Roldán, "La cuestión de la representación en el origen de la política moderna. Una perspectiva comparada (1770-1830", en La vida política en la Argentina del siglo XIX. Armas, votos y voces, ed. Hilda Sabato y Alberto Lettieri (Buenos Aires: FCE, 2003), 25-43; Roberto Gargarella, La sala de máquinas de la Constitución: dos siglos de constitucionalismo en América Latina (1810-2010) (Buenos Aires: Katz, 2014). 
En segundo lugar, la ponderación que De Vedia hizo durante más de dos décadas de enseñanza universitaria en la Facultad de Derecho de la Universidad de Buenos Aires de la teoría del estado de derecho como resultado de la autolimitación de un estado soberano, sugiere que la circulación de esta teoría en la Argentina tenía antecedentes antes de que fuera sometida a crítica en la reflexión jurídica local desde mediados de los años 1930.

Finalmente, merece subrayarse, una vez más, la crítica al liberalismo en nombre de la defensa de la libertad y de los riesgos totalitarios. Pues si semejante crítica, como se dijo, es históricamente entendible debido al papel que había desempeñado el liberalismo en la construcción del Estado en la Argentina, esa crítica, contemplada desde una perspectiva doctrinaria o teórica, o externa a las coordenadas argentinas, muestra un argumento llamativo, la libertad como un principio invocado para objetar el liberalismo.

Teniendo todo esto en consideración, y colocando nuevamente las intervenciones aquí vistas en un panorama más amplio, los rótulos «liberalismo» y «crisis» merecen replantearse, o precisarse, en tanto pueden dejar inadvertidas la circulación y la recepción de argumentaciones y de formulaciones doctrinarias que indican no sólo «supervivencias», sino efervescencia y polémicas sobre el presente y sobre el pasado del liberalismo argentino entre las décadas de 1910 y 1940.

\section{Bibliografía}

Alberdi, JuAn Bautista. Obras completas. Buenos Aires: La Tribuna Nacional, 1887.

Álvarez, Agustín. Historia de las instituciones libres. Buenos Aires: Vaccaro, 1919.

Ana Clarisa AgüEro y Alejandro Eujanián, ed. Variaciones del reformismo. Tiempos y experiencias. Rosario: Universidad Nacional de Rosario, 2018.

ANDREWS, CATHERINE, ed. Un siglo de constitucionalismo en América Latina (1917-2017). México: C.I.D.E/ Secretaría de Relaciones Exteriores/Archivo General de la Nación, 2017.

ARLOTTI, RAÚL. «Faustino J. Legón: la primera comunidad epistémica del Derecho Político en Argentina y la introducción del Derecho Político en la Universidad Nacional de La Plata». Revista Anales de la Facultad de Ciencias Jurídicas y Sociales, 47 (2017). 
ARlotti, Raúl. «Las primeras lecciones de Derecho Político del Profesor Titular Faustino J. Legón en la Facultad de Derecho y Ciencias Sociales de la UBA». En Facultad de Derecho y Ciencias Sociales. Enseñanzas de su historia, editado por Tulio Ortiz. Buenos Aires: Facultad de Derecho UBA, 2015.

ARLOTTI, RAÚL. «Las primeras lecciones de Derecho Político en la Facultad de Derecho y Ciencias Sociales de la UBA». En Nuevos Aportes a la Historia de la Facultad de Derecho de la Universidad de Buenos Aires, editado por Tulio Ortiz. Buenos Aires: Facultad de Derecho UBA, 2014.

BACOlLa, NATACHA. «A propósito de Rafael Bielsa. Semblanza para una historia de la Ciencia Política en Argentina en los inicios del siglo XX». Araucaria. Revista Iberoamericana de Filosofía, Política y Humanidades, 38 (2017): 545-573.

Bianco, José. Mis lecturas. Buenos Aires: Librería Mendensky- Augusto Sabourin e hijo, 1920.

BIANCO, JosÉ. Vida de las instituciones políticas. Buenos Aires: Rosso, 1929.

BUCHBINDER, PABLO. ¿Revolución en los claustros? La reforma universitaria de 1918. Buenos Aires: Sudamericana, 2012.

BuchBinder, PABlo. Historia de las universidades argentinas. Buenos Aires: Sudamericana, 2005.

Compagnon, Olivier. Jacques Maritain et l'Amérique du Sud. Le modèle malgré lui. Villeneuve-d'Ascq: Presses universitaires du Septentrion, 2003.

De Vedia y Mitre, Mariano. Curso de Derecho Político. Buenos Aires: Biblioteca Jurídica, 1934.

De Vedia y Mitre, Mariano. Derecho Político General. Buenos Aires: Kraft, 1952.

De Vedia y Mitre, Mariano. Historia general de las ideas políticas. Buenos Aires: Kraft, 1946.

DotTI, JoRGE. Carl Schmitt en Argentina. Rosario: Homo Sapiens, 2000.

DotTI, JoRGE. La letra gótica. Recepción de Kant en Argentina, desde el romanticismo hasta el treinta. Buenos Aires: Facultad de Filosofía y Letras, UBA, 1992.

Duguit, LEón. Soberanía y libertad. Madrid: Francisco Beltrán, 1924.

FAWCETT, Edmund. Liberalism: The Life of an Idea. Princeton University Press, 2019.

Fernando Segovia, JuAn. «Faustino Legón: del Derecho Natural al Derecho Constitucional», Anales de la Fundación Francisco Elías de Tejada, XVII (2012). 
FIoravanti, MaURizio. Los derechos fundamentales. Apuntes de historia de las constituciones. Madrid: Trotta, 2009.

Gallo, Ezequiel. Vida, libertad, propiedad. Reflexiones sobre el liberalismo clásico y la historia. Caseros: Untref, 2008.

GARGARElla, Roberto. La sala de máquinas de la Constitución: dos siglos de constitucionalismo en América Latina (1810-2010). Buenos Aires: Katz, 2014.

HALPERIN DonghI, Tulio. «Argentina: Liberalism in a Country Born Liberal». En Guiding the Invisible Hand. Economic Liberalism and the State in Latin America, editado por Joseph Love and Nils Jacobsen. New York: Praeger, 1988.

Halperin Donghi, Tulio. Vida y muerte de la República Verdadera. Buenos Aires: Ariel, 1999. Halperin Donghi, Tulio. La República Imposible (1930-1945). Buenos Aires: Ariel, 2004.

Herrera, CARLos M. «Jean Jaures y León Duguit en Buenos Aires: el político, el científico, lo social». En Visitas culturales en la Argentina, 1898-1936, editado por Paula Bruno. Buenos Aires: Biblos, 2014.

Kennedy, Ellen. Carl Schmitt en la República de Weimar. La quiebra de una constitución. Madrid: Tecnos, 2012.

Legón, Faustino. Cuestiones de política y derecho. Buenos Aires: Perrot, 1951.

LEGón, FAUSTINO. La soberanía: conceptos, formación histórica, doctrinas críticas, sentido ético. Buenos Aires: Librería Jurídica V. Abeledo, 1938.

Legón, Faustino. Tratado de Derecho Político General. Buenos Aires, Ediar, 1959.

Legón, Faustino. Tratado de Derecho Político General. Buenos Aires: Ediar, 1961.

Losada, LeAndro, comp. Política y vida pública. Argentina, 1930-1943. Buenos Aires: Imago Mundi, 2017.

LOSADA, LEANDRO. «Liberalismo y derechas en la Argentina, 1912-1943. Apuestas interpretativas, posibilidades y límites», Prismas. Revista de Historia Intelectual, 24 (2020): 219-225.

NÁlLIM, JoRGE. Transformación y crisis del liberalismo. Su desarrollo en la Argentina en el período 1930-1955. Buenos Aires: Gedisa, 2014.

Piñero, Norberto. Política. El momento presente. Problemas sociales y políticos. Estabilidad de la constitución. Buenos Aires: Menéndez, 1929.

RoldÁn, DARío, ed. Crear la democracia. La Revista Argentina de Ciencias Políticas y el debate en torno de la República Verdadera. Buenos Aires: FCE, 2006. 
Rosenblat, Helena. The Lost History of Liberalism. From Ancient Rome to the Twenty-First Century. Princeton University Press, 2019

Sabato, Hilda y LetTieri, Alberto, eds. La vida política en la Argentina del siglo XIX. Armas, votos y voces. Buenos Aires: FCE, 2003.

Sánchez Viamonte, Carlos. Derecho político (ensayos). Buenos Aires: Sagitario, 1925.

SANGUINETTI, HoRACio. «La verdad acerca de la creación del Instituto de Enseñanza Práctica». Academia. Revista sobre enseñanza del Derecho, 21 (2013).

SAntofimio Gamboa, Jaime ORLANDo. «León Duguit y su doctrina realista, objetiva y positiva del Derecho en las bases del concepto de servicio público». Revista digital de Derecho Administrativo 5 (2011).

SEGOVIA, FERNANDO. «El derecho entre iusnaturalismo, decisionismo y personalismo. Arturo Sampay lector de Carl Schmitt». Anales de la Fundación Francisco Elías de Tejada XX (2015).

SuÁREZ CoRTina, MANUEl (coord). Libertad, armonía y tolerancia. La cultura institucionista en España. Madrid: Tecnos, 2008.

TATo, MARÍa InÉs. Viento de fronda. Liberalismo, conservadurismo y democracia en la Argentina, 1911-1932. Buenos Aires: Sudamericana, 2004.

YANZI FERREIRA, RAMóN. «La enseñanza de Derecho Político en la Facultad de Derecho y Ciencias Sociales de la Universidad Nacional de Córdoba». Revista de la Facultad III, no. 2 (2012).

ZANCA, JosÉ. Cristianos antifascistas: conflictos en la cultura católica argentina, 1936-1959. Buenos Aires: Siglo XXI, 2013.

ZimMERMAnN, EdUARDo. Los liberales reformistas. La cuestión social en la Argentina, 1890-1916. Buenos Aires: Sudamericana/Universidad de San Andrés, 1995. 